\title{
EVALUATION OF INSERTION TORQUE AND INITIAL STABILITY OF TAPERED THREADED IMPLANT DEPENDING ON APICAL PORTION DESIGN SOLID IMPLANT VERSUS CORE-VENT VERSUS DOUBLE GROOVES DESIGN (AN IN VITRO STUDY)
}

\author{
Sameh Fathy El Refaiy Fouda*, Hamdy Abo Elfetoh ${ }^{* *}$, Hesham Fattouh $^{* * *}$ and Mohammed Atef ${ }^{* * *}$
}

\begin{abstract}
Aim: is to evaluate the insertion torque and initial stability of solid tapered threaded implants versus core- vent implant versus double grooved threaded implants.

Methodology: Blocks of fresh bovine bone samples were collected for the study. The bone blocks were stabilized by embedding them in dental plaster. A total of 24 implants were used for this study, a) Solid tapered threaded implants; b) double grooved threaded implants, c) Core-vent tapered threaded implants. Implant from each group was inserted in each bone block at insertion torque pre adjusted manually with a ratchet (cod BM-0292) and the maximum insertion torque was $90 \mathrm{~N} / \mathrm{cm}$, firstly each implant from each group was inserted at torque $30 \mathrm{~N} / \mathrm{cm}$ then calibrate the part of implant inserted within bone by calibrating the part of implant outside the bone using digital caliber and subtracting the measure from whole implant length $12 \mathrm{~mm}$, the same steps are done at torque $40 \mathrm{~N} / \mathrm{cm}$ and at torque $50 \mathrm{~N} / \mathrm{cm}$. The removal torque of each implant was measured after implant insertion at torque $40 \mathrm{~N} / \mathrm{cm}$ by unscrewing the fixture using a ratchet. The implants inserted until the head of the implant was flush with the surrounding bone level. RFA measurements were carried out using the Osstell device.

Results: for the length of part of implant inserted within bone at each insertion torque there was no significant difference between different groups $(\mathrm{p}=0.995)$. For the primary stability there was no sig nificant difference between different groups $(\mathrm{p}=0.990)$. For the torque removal of each group the highest value was found in group (C) (core vent implant), followed by group (B) (double grooved implant), while the lowest value was found in group (A) (solid implant) and there was a significant difference by $(\mathrm{p}=0.008)$.
\end{abstract}

Conclusions: Primary stability and insertion torque of the implant not affected by apical design of the implant with grooves or hollow chambers (vents). Removal torque is affected by the apical design of the implant. Implant designs with apical hollow chambers, from a clinical point of view, have more significance value than solid and grooved apical designs mechanically.

* Master Degree in Oral Implantology Faculty of Dentisry, Cairo University

** Professor of Removable Prosthodontics Faculty of Dentisry, Cairo University

*** Ass. Professor Oral and Maxillofacial Surgery, Faculty of Dentisry, Cairo University 


\section{INTRODUCTION}

Oral health and oral health care are very important to maintain proper mastication, digestion, phonation, appearance, and psychological well-being. The loss of one or more teeth due to any reason may adversely affect the oral health with an affected appearance being the most serious consequence for the patient and prime reason cited by the patient for seeking prosthodontics treatment. There are three basic approaches to replace a missing tooth or teeth including removable dental prosthesis, fixed dental prosthesis, and dental implants. Each alternative has its own benefits and shortcomings. It is important to consider the patient's financial, medical, and emotional condition for the best treatment.

Dental implants are currently accepted as a predictable treatment option for the rehabilitation of both partial and total edentulous patients. Moreover, immediate and early loading protocols have been introduced into clinical practice in the attempt to shorten treatment time and minimize patient discomfort, with positive results. During the early phases of healing, dental implants should be protected from detrimental micro movements which should not exceed values ranging between 50 and $150 \mathrm{~nm}$ to avoid risks for the osseointegration process. When exceeding this threshold, there is a concrete possibility that the bone-implant interface could be colonized by fibroblasts from the overlying connective tissue, with consequent implant encapsulation in fibrous tissue and clinical failure. In this scenario, the role of primary stability has become extremely important and, in recent years, many studies focused on this crucial topic.

Implant stability is defined as the absence of movement at the moment of measurement. This factor can be measured at the moment of implant placement (primary stability) or once the osseointegration process is underway (secondary stability). Both parameters are interrelated positively. Traditionally, a high primary stability was associated with expectation of good secondary stability, which would ensure the likelihood of implant success and osseointegration. Consequently, poor primary sta- bility was thought to be one of the major causes of implant failure. Primary implant stability is influenced by many factors including local bone quality and quantity, and implant macro-design. The treatment modalities of the implant surface may also ameliorate the primary stability. Since bone quality is a given factor that cannot be altered, adaptation of the implant surface and design to the specific qualities of the host bone should be done to promote osseointegration.

Implant design refers to the three-dimensional structure of the implant. Dental implants are subjected to various force magnitudes and directions during function, functional design objectives should aim to manage biomechanical loads to optimize the implant-supported prosthesis function. An implant has a macroscopic body design and a microscopic component of implant design. The macroscopic implant body design is most important during implant insertion to provide better primary stability required for immediate loading while the microscopic features are most important for implant during healing period to achieve proper osseointegration.

Most root form implants are circular in crosssection. Round cross-sections, however, do not resist torsion/shear forces when abutment screws are tightened or when freestanding, single-tooth implants receive a rotational (torsional) force. As a result, an antirotational feature is incorporated into the implant body, usually in the apical region. The most common designs are grooves within apical portion or hole or vent.

Historically, implant stability and osseointegration have been assessed using various techniques, including insertion torque, percussion testing and radiographic analysis. Loading protocols and healing time for individual patients are often empirically calculated based on clinical research studies evaluating implant stability and osseointegration over time. Resonance frequency analysis (RFA) provides a noninvasive, objective method of assessing implant stability over time. 
Thus, the aim of the current study is to evaluate the insertion torque, primary stability and removal torque of solid tapered threaded implant versus double grooved implant at apical portion versus implant with hollow chamber (vent) at apical portion.

\section{AIM OF THE STUDY}

The aim of the current study was to evaluate the insertion torque and initial stability of solid tapered threaded implants versus implant with hollow chamber (vent) versus double grooved threaded implants.

\section{MATERIALS AND METHODS}

\section{Materials}

\section{Sample size calculation}

A power analysis was designed to have adequate power to apply a 2-sided statistical test of the alternative hypothesis that there will be a significant difference between solid tapered threaded implants versus core-vent implant versus double grooved threaded. According to the results of Nokar, Saied, et al.-in which the $(M e a n \pm S D)$ values of insertion torque for the tested groups were $(14.86 \pm 2.8)$, $(12.88 \pm 2.13)$ and $(19.00 \pm 5.67)$ - by adopting an alpha level of $(0.05)(5 \%)$, beta level of $(0.20)$ $(20 \%)$ i.e. power of the study $(0.8)(80 \%)$ and an effect size (f) of (0.72); The predicted sample size (n) was a total of (24) samples i.e. (8) samples per group. Sample size calculation was performed using
G*Power version3.1.9.2.

\section{Implants}

A total of twenty four (24) threaded implants were turned from Grade 23 titanium rods with an external diameter of $4.1 \mathrm{~mm}$ and a total length of 12 $\mathrm{mm}$ and fabricated using Swiss type lathe star SR20JII (Star Micronics GB LtdC by the manufacturer (Dual Implant titan, Egypt).

All implants were identical on the coronal and middle third of the implant, the only difference between the groups was the design on the apical third of the implants. All implants divided into three groups depending on apical design, group (A), group (B) and group (C). Implants in group (A) had a self-tapping solid design without any grooves or vents. Implants in group (B) had a self-tapping apical design with centric cutting grooves. Implants in group (C) had a hollow chamber (vent) apically as shown in (figure 1).

\section{Bone blocks}

Blocks of fresh bovine bone samples are collected from a cow mandible for the study and this is approved by institutional animal care and use committee (CU-IACUC) Cairo University. Bovine bones used in this study because of the similarities between bovine bone and human bone in terms of density and relationship between cortical and cancellous bone (El-kholey et al., 2017).

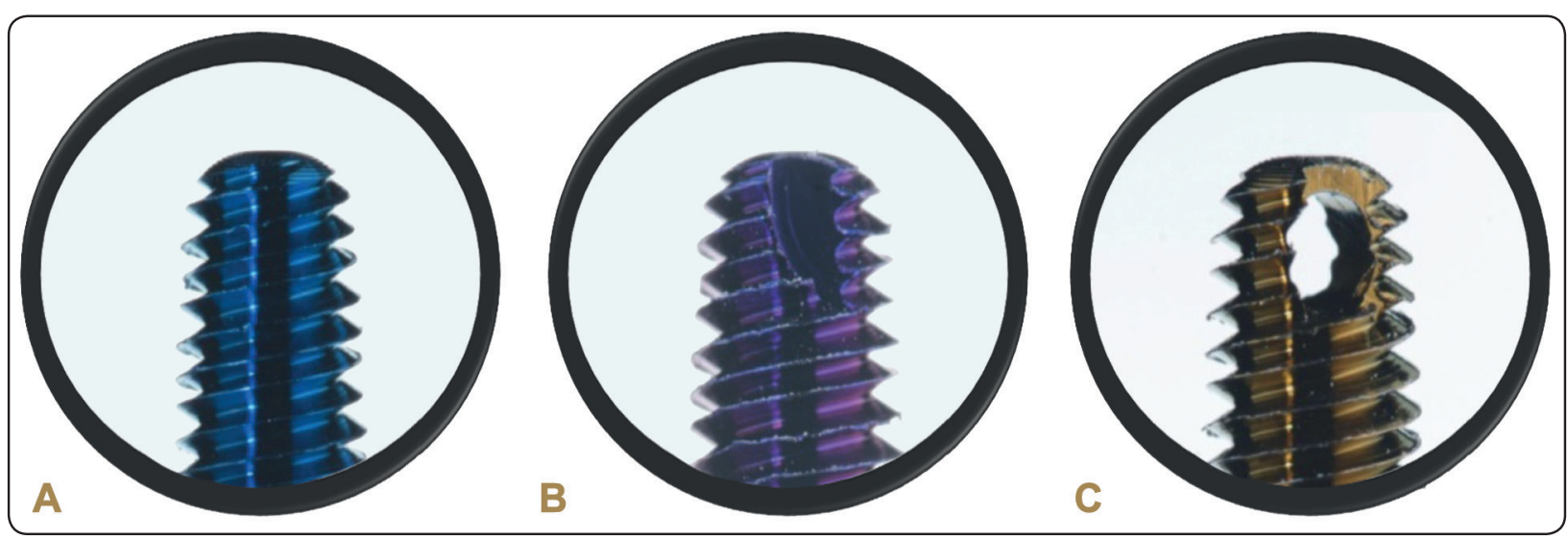

Fig. (1): implant design a) Solid implant (blue) b) Implant with apical double grooves (purple) c) Implant with apical vent (bronze) 
The samples are cleaned and removed of all soft-tissue residues, and divided into 8 blocks with the following dimensions: $50 \mathrm{~mm}$ length, $40 \mathrm{~mm}$ height and $15 \mathrm{~mm}$ width. To minimize changes in bone thermo-physical and mechanical proprieties, the specimens froze till use under $18{ }^{\circ} \mathrm{C}$ then left three hours before starting the experiment at room temperature $\left(37^{\circ} \mathrm{C}\right)$ to permit bone blocks to restore some of their elasticity. Bone blocks fixed in plaster blocks for stabilization.

\section{Methods}

The implants placement and calibrating the Lengths of implants inserted within bone at different insertion torques

All implants were individually inserted into the bone blocks by a single operator. The drilling was performed with a Surgical Electric Motor (woodpecker implant-X(C) using copious irrigation, adjusted to a torque of $50 \mathrm{~N}$ and $1300 \mathrm{rpm}$. The drilling protocol followed the manufacturer's recommendations for each osteotomy for standardization, the sequence of drills in order as following: $2.2 \mathrm{~mm}$, $2.8 \mathrm{~mm}, 3.4 \mathrm{~mm}$, and $3.8 \mathrm{~mm}$.

Implant from each group is inserted in each bone block at insertion torque pre adjusted manually with a ratchet (multi-setting torque wrench TWM, Implant Direct ${ }^{\mathrm{TM}}$ ), firstly each implant from each group inserted at torque $30 \mathrm{~N} / \mathrm{cm}$ then calibrate the part of implant inserted within bone by calibrating the part of implant outside the bone using a digital precise caliper (Ruifeng Foreign, China) and subtracting the measure from whole implant length 12 $\mathrm{mm}$. for example, if the reading of the part of implant outside the bone measured by caliper was 3.27 $\mathrm{mm}$, we calibrate the part of implant inserted within bone according to equation $(12 \mathrm{~mm}-3.27 \mathrm{~mm}=$ $8.73 \mathrm{~mm}$ ).

The same steps are done at insertion torque $40 \mathrm{~N} /$ $\mathrm{cm}$ and insertion torque $50 \mathrm{~N} / \mathrm{cm}$.

\section{Removal torque}

The removal torque of each implant is measured after implant insertion at torque $40 \mathrm{~N} / \mathrm{cm}$ by unscrewing the fixture using a ratchet (multi-setting torque wrench TWM, Implant Direct ${ }^{\mathrm{TM}}$ ) and notes the torque that the implant unscrewed at it.

\section{Primary stability measurements using Resonance Frequency Analysis (RFA)}

The primary stability of each implant was assessed via insertion torque and resonance frequency analysis. Primary stability was measured at the time of implant installation in the block until the implant reached the ideal position using the torque wrench. Resonance frequency analysis was performed with the Osstell ${ }^{\mathrm{TM}}$ Mentor (Integration Diagnostics Ltd., Göteborg, Sweden). This device uses a piezoelectric effect to produce a deflection of the implant on the transducer (smart peg), which was adapted directly over the implant and was stimulated to vibrate by means of sinusoidal waves. The implant stability (ISQ) measured by this device was measured on a scale from 1 (minimum) to 100 (maximum).

The torque wrench and the Osstell were calibrated before and after the measurements of each implant. The measurements were repeated 3 times in each implant, and the average of this value was considered the value of the sample.

\section{Statistical analysis}

Data were explored for normality using Kolmogorov-Smirnov and Shapiro-Wilk tests and were found to be normally distributed. One-way ANOVA followed by Tukey's post hoc test was used for intergroup comparisons while one-way repeated measures ANOVA followed by Bonferroni post hoc test was used for intragroup comparisons. The significance level was set at $\mathrm{p} \leq 0.05$ for all tests. Statistical analysis was performed with IBM ${ }^{\circledR}$ SPSS $®$ (SPSS Inc., IBM Corporation, NY, USA) Statistics Version 26 for Windows. 


\section{RESULTS}

\section{1- Lengths of the implants inserted within bone at different insertion torques}

\section{A- Intergroup comparisons:}

\section{-30N:}

The highest value of the length of part of implant inserted within bone was found in groups (A) (7.92 \pm 0.66$)$ and (B) $(7.92 \pm 0.56)$, while the lowest value was found in group $(\mathrm{C})(7.90 \pm 0.65)$ and there was no significant difference between different groups ( $\mathrm{p}=0.996)$.

\section{-40N:}

The highest value of the length of part of implant inserted within bone was found in group (A) (8.49 \pm 0.66$)$, followed by group (B) $(8.48 \pm 0.59)$, while the lowest value was found in group (C) $(8.45 \pm 0.64)$ and there was no significant difference between different groups $(\mathrm{p}=0.988)$.

\section{-50N:}

The highest value of the length of part of implant inserted within bone was found in group (A) $(8.96 \pm 0.67)$, followed by group (B) $(8.95 \pm 0.65)$, while the lowest value was found in group (C) $(8.94 \pm 0.67)$ and there was no significant difference between different groups $(\mathrm{p}=0.999)$.

\section{- Average:}

The highest value of the length of part of implant inserted within bone was found in group (A) (8.46 \pm 0.66$)$, followed by group (B) $(8.45 \pm 0.60)$, while the lowest value was found in group (C) $(8.43 \pm 0.65)$ and there was no significant difference between different groups $(\mathrm{p}=0.995)$.

\section{B- Intragroup comparisons:}

\section{Group (A) (solid implants):}

The highest value of the length of part of implant inserted within bone was measured at $(50 \mathrm{~N})$
$(8.96 \pm 0.67)$, followed by $(40 \mathrm{~N})(8.49 \pm 0.66)$, while the lowest value was found at $(30 \mathrm{~N})(8.96 \pm 0.67)$ and there was a significant difference between different torque values $(\mathrm{p}<0.001)$. Pairwise comparisons showed values of different torques to be significantly different from each other $(\mathrm{p}<0.001)$.

\section{Group (B) (grooved implants):}

The highest value of the length of part of implant inserted within bone was measured at $(50 \mathrm{~N})$ $(8.95 \pm 0.65)$, followed by $(40 \mathrm{~N})(8.48 \pm 0.59)$, while the lowest value was found at $(30 \mathrm{~N})(7.92 \pm 0.56)$ and there was a significant difference between different torque values $(\mathrm{p}<0.001)$. Pairwise comparisons showed values of different torques to be significantly different from each other $(\mathrm{p}<0.001)$.

\section{- Group (C) (implants with hollow chambers):}

The highest value of the length of part of implant inserted within bone was measured at $(50 \mathrm{~N})$ $(8.94 \pm 0.67)$, followed by $(40 \mathrm{~N})(8.45 \pm 0.64)$, while the lowest value was found at $(30 \mathrm{~N})(7.90 \pm 0.65)$ and there was a significant difference between different torque values $(\mathrm{p}<0.001)$. Pairwise comparisons showed values of different torques to be significantly different from each other $(\mathrm{p}<0.001)$.

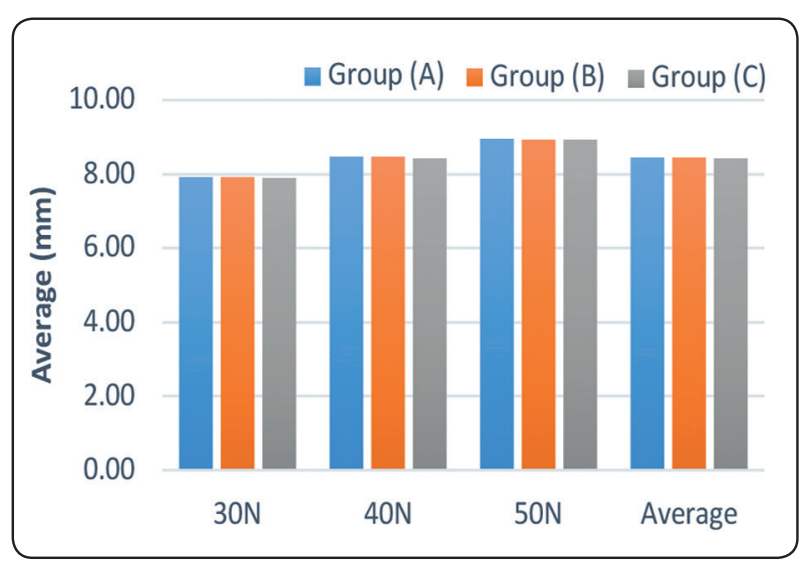

Fig. (2): Bar chart showing the average of lengths of the implants inserted within bone at different implant insertion torques (mm). Group (A) solid implants, Group (B) grooved implants, and Group (C) implants with hollow chambers 


\section{2- Primary stability}

Mean and standard deviation (SD) values for primary stability (ISQ readings) were presented in figure (3)

The highest value was found in group (C) $(69.00 \pm 8.43)$, followed by group (B) $(68.75 \pm 9.42)$, while the lowest value was found in group (A) $(68.38 \pm 9.20)$ and there was no significant difference between different groups $(\mathrm{p}=0.990)$

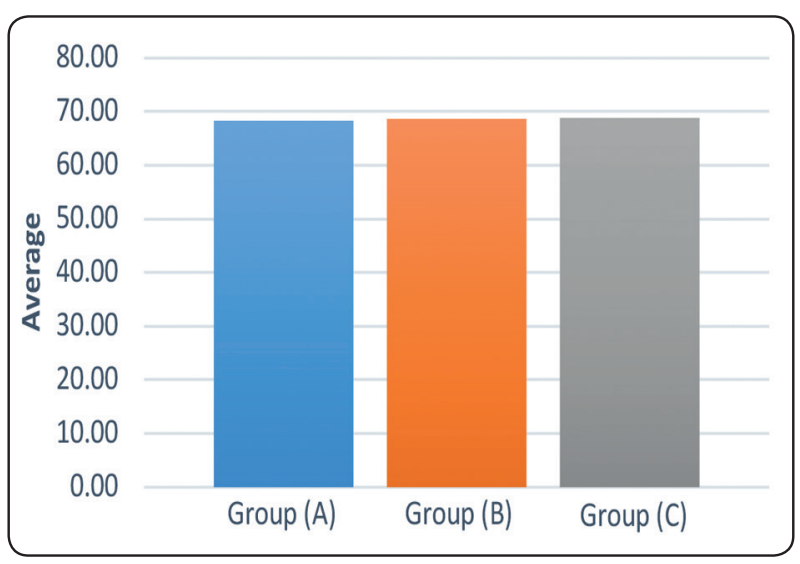

Fig. (3): Bar chart showing average primary stability (ISQ readings) Group (A) solid implants, Group (B) grooved implants, and Group (C) implants with hollow chambers

\section{3- Removal torque}

Values of removal torque of each implant of each group after insertion torque at $40 \mathrm{~N}$ are shown in figure (4) The highest value was found in group (C)

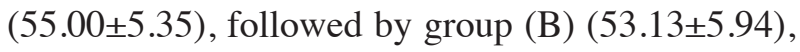
while the lowest value was found in group (A) $(46.88 \pm 2.59)$ and there was a significant difference between different groups $(\mathrm{p}=0.008)$. Pairwise comparisons showed value measured in group (A) to be significantly lower than values of other groups $(\mathrm{p}<0.001)$.

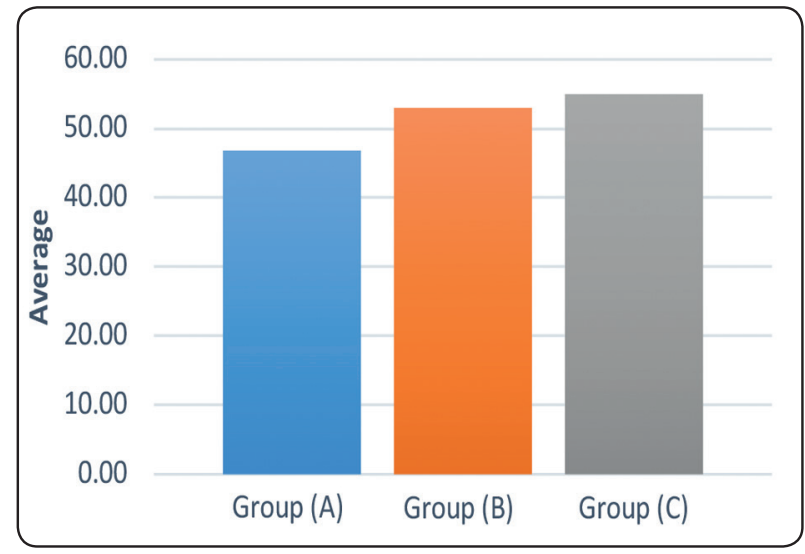

Fig. (4): Bar chart showing average removal torque

\section{DISCUSSION}

Branemark, in 1983 defined Osseointegration as the direct structural and functional connection between the living bone and surface of a loadbearing implant. The ability of an implant to bond with the surrounding host bone is another fundamental requirement for permanent orthopedic implants. Insufficient osseointegration can lead to the formation of fibrous tissues and ensuing loosening of the prostheses. Factors such as the design, chemical composition, surface roughness, and surface chemistry of the implants and loading conditions are important to good osseointegration of implants (Mavrogenis et al, 2009).

Primary stability is considered of paramount importance to achieve osseointegration. Implant stability is achieved at two different stages: primary and secondary. The primary stability of an implant comes from mechanical engagement with the cortical bone. It is affected by the quality and quantity of bone that the implant inserted into, surgical procedure, length, diameter, and form of implant. There are some essential prerequisites for the possibility of immediate loading: selection of an implant system with great primary stability, high bone-implant surface contact, and reduction of micro-motion to $<100 \mathrm{~nm}$. (D. Baldi, et al 2011). 
Implant design refers to the three-dimensional structure of the implant, with all the elements and characteristics that compose it. An implant has a macroscopic body design and a microscopic component of implant design. The macroscopic implant body design is most important during implant insertion to provide better primary stability required for immediate loading while the microscopic features are most important for implant during the healing period to achieve proper osseointegration. (Yadav et al., 2016).

Today, the most commonly used implant design is a tapered screw, with a moderately rough implant surface, thus facilitating one-stage surgical procedures and allowing for immediate or early loading protocols. Our study was designed to evaluate the effect of different dental implant apical designs on the insertion torque, primary stability of dental implant which is necessary for implant osseointegration and immediate loading in addition to the effect of dental implant apical design on the removal torque as an antirotational feature. For this purpose this study used threaded tapered implants have a self-tapping solid design without any grooves or vents as in group (A), threaded tapered implants have a self-tapping apical grooves as in group (B), threaded tapered implants have hollow chambers apically as in group (C).

Most root-form implants are circular in crosssection that don't resist torsion and shear forces when abutment screws are tightened or under mastication forces, especially in single-tooth implants. As a result, it was mandatory to incorporate an antirotational feature into the implant body. The most common antirotational designs are grooves and hollow chambers within the apical portion of the implant. In our study, all implants were identical on the coronal and middle third of the implant and the only difference between the groups was the design of the apical third of the implants to assess the effect of apical design on primary stability and removal torque.
The apical hollow chamber increases the surface area of the implant body and has the ability to transmit compressive loads to the bone. Another advantage of the apical vent is that bone can grow through the apical hole and resist torsional loads applied to the implant. A disadvantage of the apical hollow chamber occurs when the implant is placed through the sinus floor or becomes exposed through a cortical plate because the apical hole may fill with mucus and become a source of retrograde contamination or the fibrous tissues may migrate throw the chamber. Short implants can't be provided with vents as they weaken the body of short implants and they will not allow machining of a proper internal connecting screw.

Another antirotational feature of an implant body may be flat sides or grooves along the body or apical region of the implant body. The bone grows against the flat or grooved region and helps to resist torsional loading. Also, the grooves of the apical portion of the implant help to enhance the "self-tapping" aspect of an implant design because machining of apical grooves subsequently create sharp edges that make implant insertion much easier and less torque is required to thread the implant into the bone. Also, the apical end of each implant should be flat rather than pointed. Pointed geometry has less surface area, thereby raising the stress level in that region of bone.

In experimental, in vitro studies, several methods and materials are used to simulate human bone such as animal bone or synthetic materials. Animal bones originate usually from pig or bovine including ribs, mandible, femur, iliac crest, rarely from sheep. Synthetic materials include polyurethane (PU), polymethyl-methacrylate (PMMA), or hydroxyl-apatite and in other studies resin and hardwood were used. In our study, the bovine bone was used because of the similarities between bovine bone and human bone in terms of density. Bone blocks were taken from the mandible as it resembles the human mandible in the outer cortical layer and inner cancellous bone. 
There are many differences between bone models used in in vitro studies and vital bone such as bone elasticity, bone dryness because there is no blood circulation in the bone models, the environmental temperature is not the oral but room temperature and no physiological reactions occur such as osteolysis and osteogenesis. In our study, we preferred to use bovine bone blocks because of availability, repeatability, easy manipulation and to decrease time-consuming and decrease the cost. We tried to decrease the drawbacks of invital bone blocks usage by preserving the specimens under $18{ }^{\circ} \mathrm{C}$ then left three hours before starting the experiment at room temperature $\left(37^{\circ} \mathrm{C}\right)$ to permit bone blocks to restore some of their elasticity.

Fernandes M. G et al in 2017 made a study about the heat generation during bone preparation and drilling time in different bone simulating materials such as bovine rib, pig rib, polyurethane blocks and poly-methyl-methacrylate (PMMA) and compared them to fresh human cadaver rib. They reported that the bovine rib shows significantly higher temperature elevations and slower preparation times than human bone so in our study, copious irrigation with precooled saline was used to overcome the heat generation during bone preparation and we followed the manufacturer's recommendations in drilling protocol for each osteotomy with slight modification by drilling to implant exacting size. Torque and ISQ values obtained with a bone model from our study can be relatively compared with the corresponding values obtained from other studies under the same conditions.

Several assessment methods such as histologic assessments and mechanical testing like pull-out, push-out, and torque measurement are used for measuring implant stability. Histologic assessments are only used for osseointegrated implants. In our study, we used threaded tapered implants and tried to assess primary stability and removal torque after implant insertion before osseointegration. Therefore, this study used the insertion torque and reverse-torque test as a proper method for primary stability evaluation as Push-out and pull-out tests are indicated with cylindrical or press-fit implants.

Insertion torque is the measure of the frictional resistance produced by the implant while moving forward apically through a rotatory movement on its axis and it is indirectly a value of the primary implant stability. The insertion torque value is a result of the host jaw bone texture, drilling protocol, and implant design. Some experienced implant surgeons modify in drilling protocol to increase and manipulate the insertion torque value. (Johansson P, 1994) In our study, drilling protocol according to manufacturer's recommendations was fixed to correlate the insertion torque values to different apical designs.

Shokri et al in 2013 reported that Resonance Frequency Analysis (RFA) provides a non-invasive, objective method of assessing implant stability over time. However, other studies reported about Osstell ISQ's reliability upon measurement. Reliability is measured using concepts such as repeatability (several attempts with the same transducer lead to similar results), and reproducibility (different transducers on the same implant provide similar data). The differences in readings of Osstell ISQ's values may be due to the transducer (smart peg) not compatible with the internal threads of the implant, fastening torque to the smart peg may differ from operator to another and the distance between the hand piece and the transducer (smart peg) that may also differ from operator to another. The lack of data on Osstell's reliability had to be overcome by completing several registers and calculating the mean value as made in our study. Meredith in 1996 studied the first generation of the Osstell system, and found high repeatability, but referring that though the transducer's tightening torque was the only torque variable that can distort readings. Mariano

Herrero-Climent in $\mathbf{2 0 1 3}$ made a study on the last generation of the Osstell system (Osstell ISQ) and reported higher repeatability and reproducibility than Meredith's study. 
The correlation between insertion torque and ISQ has been investigated in numerous studies. Some authors proved that two parameters are in a direct relationship and other studies demonstrated no statistically significant correlations between them. Domenico Baldi et al in $\mathbf{2 0 1 8}$ evaluate the correlation between insertion torques (IT) and implant stability quotient (ISQ) in tapered implants with knife-edge threads by inserting Seventy-five identical implants using the same drilling protocol. They reported that ISQ and IT showed a positive correlation up to values around $50 \mathrm{~N} / \mathrm{cm}$

The reverse torque test proposed by Roberts et al.in 1984 represents a definitive clinical verification of the initial integration of the dental implant with the bone surface. The torque level required is commonly expressed in Newton centimeters ( $\mathrm{Ncm}$ ). The clinical evaluation is made of the perception of any movement of the dental implant after a specific counterclockwise force. The reverse torque test is measured with the torque controller device or torque meter or manual ratchet. In the present study, the ratchet was used as a main device for recording values of insertion torque and removal torque because of availability and simplicity in addition to the cost.

The present study concentrated on the effect of the apical design of implants on insertion torque, primary stability, and removal torque after implant insertion before osseointegration. From the results, mechanically we found that apical design with grooves and hollow chamber don't affect the implant insertion or primary stability of the implant while removal torque was affected by apical design as the highest values of removal torque were found in apical design with a hollow chamber (group C) followed by apical design with grooves (group B) which mean that grooves and hollow chambers act as antirotational features. Our readings coincide with the readings of the study of Luiz Meirelles et al in 2013 that compared grooved implant design and hollow chamber apical design during the period of healing and osseointegration histologically. They made a histological evaluation of bone formation adjacent to dental implants with apical chamber design and grooved implant design and reported that the presence of an apical hollow chamber minimize the effect of trauma from surgery resulting in improved wound healing as they observed after 1 week of healing, initial solitary woven bone formation (early mineralization) inside the threads of implants with vents while there weren't any signs of early mineralization in grooved. After 4 weeks, the presence of osteons surrounded by lamellar structures with centric osteocytes indicates a faster organization of bone tissue at the implants with the hollow chamber. Grooved implants showed the similar bone area with less organized tissue and reduced bone-implant contact values. From the readings of our study and Luiz Meirelles study, implant designs with apical hollow chambers, from a clinical point of view, have more significance value than solid and grooved apical designs mechanically and histologically.

The present study found that implant insertion torque and primary stability of the implant not affected by apical design with grooves and hollow chamber while removal torque was affected by apical design with a hollow chamber followed by apical design with grooves followed by solid implants without grooves or vents. Our readings are unlike the results of Saied Nokar et al, in 2018 which made a comparison of primary stability of four different implant designs, Zimmer Tapered Screw-Vent implant which has an apical hollow chamber, Noble Replace Tapered implant which has no grooves or vents, Replace Select Tapered Nobel implant which has also no grooves or vents and Dentium Super Line implant which has apical grooves. They found that the primary stability of different implant systems was not equal as the Zimmer Tapered Screw-Vent implant had a significantly lower amount of insertion torque in comparison to other systems. ISQ value in Noble Replace Tapered implant with solid body design was 
significantly higher than other systems. The reverse torque value was significantly lower in Zimmer Tapered Screw-Vent implant in comparison to other systems. In Nokar's study they compared different four implant designs including thread design and tapering of implants. In our study, there was optimum standardization in all features of implants including thread design, implant diameter, tapering degree and the only difference was in apical design which means that our results are more reliable.

\section{CONCLUSION}

Primary stability and insertion torque of the implant not affected by apical design of the implant with grooves or hollow chambers (vents).

Removal torque is affected by the apical design of the implant. Implant designs with apical hollow chambers, from a clinical point of view, have more significance value than solid and grooved apical designs mechanically.

\section{REFERENCES}

- Abdulaziz Basha-Hijazi, Bhumija Gupta, Yan-Fang Ren, Hans Malmstrom, (2014) Role of clinician's experience and implant design on implant stability. An ex vivo study in artificial soft bones. Clin Implant Dent Relat Res 16(2):166-71.

- $\quad$ Adell R, Lekholm U, Rockler B, (1981). A 15-year study of osseointegrated implants in the treatment of the edentulous jaw. Int J Oral Surg; 10:387-416

- AlbrektssonT. JohanssonC, (2001). Osteoinduction, osteoconduction and osseointegration. European Spine Journal, 10Suppl.2, 961010940-6719

- Albrektsson T. (1983). Direct bone anchorage of dental implants. J Prosthet Dent. 50:255-261.

- Bischof M, Nedir R, Szmukler-Moncler S, Bernard JP, Samson J, (2004). Implant stability measurement of delayed and immediately loaded implants during healing. Clin Oral Implants Res 15:529-539

- $\quad$ Block MS, Kent JN: (1990). Factors associated with soft and hard tissue compromise of endosseous implants, J Oral Maxillofac Surg 48:1153-1160.
- Bolind PK, Johansson CB, Becker W, Langer L, Sevetz EB Jr, Albrektsson. (2005). A descriptive study on retrieved non-threaded and threaded implant designs. Clin Oral Implants Res.; 16(4): 447-455.

- Branemark R, Branemark PI, Rydevik B, Myers RR. (2001). Osseointegration in skeletal reconstruction and rehabilitation. A review. JRRD; 38(2), 175-81.

- Bumgardner, J.D. (2000). Preliminary evaluation of a new dental implant design in canine models. Implant Dent, $9,252-260$

- Chong L, Khocht A, Suzuki JB, Gaughan J, (2009). Effect of implant design on initial stability of tapered implants. J Oral Implantol 35, 130-135.

- D. Baldi, M. Longobardi, C. Cartiglia et al., (2011). “Dental implants osteogenic properties evaluated by cDNA microarrays," Implant Dentistry, vol. 20, no. 4, pp. 299-305.

- Dee K, C.Puleo D, Bizios R, (2002). An Introduction To Tissue-Biomaterial Interactions. John Wiley\&Sons, 978-047125-394-5New Jersey, US

- Domenico Baldi, Teresa Lombardi, Jacopo Colombo, Gabriele Cervino, Giuseppe Perinetti , Roberto Di Lenarda , and Claudio Stacchi (2018). Correlation between Insertion Torque and Implant Stability Quotient in Tapered Implants with Knife-Edge Thread Design. Department of Surgical Sciences, University of Genoa, Italy. Hindawi BioMed Research International, Article ID 7201093, 7 pages.

- Falisi, G., Severino, M., Rastelli, C., Bernardi, S., Caruso, S., Galli, M., Lamazza, L. and Di Paolo, C, (2017). 'The effects of surgical preparation techniques and implant macro-geometry on primary stability: An in vitro study'. Medicina ral, Patologia Oral y Cirugia Bucal, 22 (2):e201.

- Fernandes, M. G., Fonseca, E. M. M., Jorge, R. N., Vaz, M. \& Dias, M. I, (2017). Thermal analysis in drilling of ex vivo bovine bones. J. Mech. Med. Biol. 17, 1750082

- $\quad$ Friberg B, Ekestubbe A, Mellström D, Sennerby L, (2001). Brånemark implants and osteoporosis: A clinical exploratory study. Clin Implant Dent Relat Res 3, 50-56.

- Friberg B, Sennerby L, Gröndahl K, Bergström C, Bäck T, Lekholm U. (1999). On cutting torque measurements during implant placement: A 3-year clinical prospective study. Clin Implant Dent Relat Res 1:75-83.

- Friberg B, Sennerby L, Roos J, Johansson P, Strid CG, Lekholm U. (1995). Evaluation of bone density using cutting resistance measurements and microradiography: An in vitro study in pig ribs. Clin Oral Implants Res; 6:164-71. 
- Frost, H.M. (1990). Skeletal structural adaptations to mechanical usage (SATMU): redefining Wolff law: the bone modeling problem. Aanat Rec, 226,403-413.

- Hermann JS, Schoolfield JD, Nummikoski PV, Buser D, Schenk RK, Cochran DL. (2001). Crestal bone changes around titanium implants: a methodologic study comparing linear radiographic with histometric measurements. Int J Oral Maxillofac Implants; 16:475-85.

- Huang HM, Chiu CL,Yeh CY, Lin CT, Lin LH, Lee SY. (2003). Early detection of implant healing process using resonance frequency analysis.Clin Oral Implants Res 14:437-443.

- Hürzeler MB, Quiñones CR, Schüpbach P, Vlassis JM, Strub JR, Caffesse RG. (1995) Influence of the suprastructure on the peri-implant tissues in beagle dogs. Clin Oral Implants Res; 6:139-48.

- Indira G. Sahiwal, Ronald D. Woody, Byron W. (2002). Baylor College of Dentistry, Texas A\&M University System, Dallas, Texas; Macro design morphology of endoseous dental implants; J Prosthet Dent; 87:543-51.

- Jaffin RA, Berman CL: (1991). The excessive loss of Branemark fixtures in type IV bone: A 5-year analysis. J Periodontol 62, 2-4

- Johansson P, Strid K. (1994). Assessment of bone quality from cutting resistance during implant surgery. Int J Oral Maxillofac Implants 9:279-288.

- Johansson C, Albrektsson T (1987). Integration of screw implants in the rabbit: A 1-year follow-upof removal torque of titanium implants. Int J Oral Maxillofac Implants 1987;2:69-75.

- Karl, M. and Grobecker-Karl, T., (2018). 'Effect of bone quality, implant design, and surgical technique on primary implant stability'. Quintessence International, 49.

- Kohn, D.H. (1992). Overview of factors important in implant design. J Oral Implanto, 18,204-219.

- Lachmann S, Laval JY, Axmann D, Weber H. (2011). Influence of implant geometry on primary insertion stability and simulated peri-implant bone loss: An in vitro study using resonance frequency analysis and damping capacity assessment. Int J Oral Maxillofac Implants; 26:347-55.

- $\quad$ Lages, F.S., Dhelfeson Oliveira, D.W. and Costa, F.O., (2018). 'Relationship between implant stability measurements obtained by insertion torque and resonance frequency analysis: A systematic review'. Clinical Implant Dentistry and Related Research, 20 (1):26-33
- $\quad$ Levin, L., Frankenthal, S., Zigdon, H., Suzuki, M. and Coelho, P.G., (2012). 'Novel implant design for initial stability of dental implants inserted in fresh extraction sockets: A preliminary study'. Implant dentistry, 21 (4):302305 .

- Linkow LI. (1990) Implant dentistry today: a multidisciplinary approach, Volume III. Italy: Piccin Padua;: 151318.)

- Luiz Meirelles, Per-Ingvar Brånemark, Tomas Albrektsson, Changyong Feng, (2013). Histological Evaluation of Bone Formation Adjacent to Dental Implants with a Novel Apical Chamber Design: Preliminary Data in the Rabbit Model,. Wiley Periodicals

- Ma, P., Xiong, W., Tan, B., Geng, W., Liu, J., Li, W., \& Li, D. (2014). Influence of thread pitch, helix angle, and compactness on micromotion of immediately loaded implants in three types of bone quality: a three-dimensional finite element analysis. BioMed research international, 2014.

- Mahdi Kadkhodazadeh , Ardeshir Lafzi, Saeed Raoofi, Maryam Khademi, Reza Amid, Mohammad Reza Movahhedy ,Sharif University of Technology, Tehran, Iran.(2014) Comparison of the Effects of Different Implant Apical Designs on the Magnitude and Distribution of Stress and Strain in Bone: A Finite Element Analysis Study - Journal of Long-Term Effects of Medical Implant pages 109-119

- Meredith N, Alleyne D, Cawley P. (1996). Quantitative determination of the stability of the implant-tissue interface using resonance frequency analysis. Clin Oral Implants Res 7:261-7)

- $\quad$ Meredith N, Book K, Friberg B, Jemt T, Sennerby L. (1997). Resonance frequency measurements of implant stability in vivo. A crosssectional and longitudinal study of resonance frequency measurements on implants in the edentulous and partially dentate maxilla. Clin Oral Implants Res; 8:226-233.

- Meredith N, Shagaldi F, Alleyne D, Sennerby L, Cawley P. (1997). The application of resonance frequency measurements to study the stability of titanium implants during healing in the rabbit tibia. Clin Oral Implants Res;8:234-243.

- Misch CE, Misch CM: (1992). Generic terminology for endosseous implant prosthodontics, J Prosthet Dent 68:809-812,

- $\quad$ Misch CE. (1999) Contemporary Implant Dentistry. $2^{\text {nd }}$ ed. USA: Mosby publication 239-250.]. 
- Misch CE., (2005). Dental implant prosthetics, St LouisCo,Pp23-29)

- Misch, C.E. et al. (2008). Scientific rationale for dental implant design. In: Misch, C.E., ed. Contemporary Implant Dentistry. 3rd edition, 200-229. St Louis: Mosby.

- Naroa Lozano-Carrascal, Oscar Salomó-Coll, Marta Gilabert-Cerdà, Nuria Farré-Pagés, Jordi Gargallo-Albiol, and Federico Hernández-Alfaro (2016). Effect of implant macro-design on primary stability: A prospective clinical study ; Med Oral Patol Oral Cir Bucal; 21: 214-221.

- $\quad$ Nedir R, Bischof M, Szmukler-Moncler S, Bernard JP, Samson J. (2004). Predicting osseointegration by means of implant primary stability. Clin Oral Implants Res; 15:520-8.

- Nokar S, Rasouli-Ghahroudi AR, Shidvash E, Atri F.(2019). Comparative investigation of primary stability of four different dental implants in low-density bone model. Dent Res J; 16:18-23.

- O'Sullivan D, Sennerby L, Meredith N: (2004). Influence of implant taper on the primary and secondary stability of osseointegrated titanium implants. Clin Oral Implants Res $15,474-480$

- $\quad$ Olive J, Aparicio C (1990). Periotest method as a measure of osseointegrated oral implant stability. Int J Oral Maxillofac Implants 5, 390-400

- Orsini, E, Giavaresi, G, Trirl“., ., Ottani, V. and Salgarello, S., (2012). 'Dental implant thread pitch and its influence on the osseointegration process: an in vivo comparison study'. International Journal of Oral \& Maxillofacial Implants, 27.

- Osborn J.F.(1979). Biomaterials and their application to implantation. SSO Schweizerische Monatsschrift für Zahnheilkunde 8911113811390036-7702.

- OshidaY, TunaE, AktorenA, GencayK. (2010). Dental Implant Systems. International Journal of Molecular Sciences, 114158016781422-0067.

- P.I. Branemark, (1983) Osseointegration and its experimental background. JPD, 50: 399-410.

- Raghavendra S, Wood MC, Taylor TD, (2005). Early wound healing around endosseous implants: A review of the literature. Int J Oral Maxillofac Implants; 20:425-431.

- Rasmussen GHR. (1992). The Branemark System of Oral Reconstruction: A Clinical Atlas. 1st ed. Tokyo: Medico Dental Media International;. 1-4.)
- $\quad$ Roberts WE, Smith RK, Zilberman Y,Mozsary PG, Smith RS. (1984). Osseous adaptation to continuous loading of rigid endosseous implants.Am J Orthod; 86:95-111

- Romanos GE (2009). Bone quality and the immediate loading of implants - Critical aspects based on literature, research, and clinical experience. Implant Dent 18, 203209.

- Roos J, Sennerby L, Albrektsson T: (1997). An update on the clinical documentation on currently used bone anchored endosseous oral implants. Dent Update 24, 194-200

- $\quad$ Ryu HS, Namgung C, Lee JH, Lim YJ. (2014). The influence of thread geometry on implant osseointegration under immediate loading: a literature review. J Adv Prosthodont 6: 547-554.

- Schroeder A, Vander Zypen E, Sutter F, (1981). The reaction of bone, connective tissue and epithelium to endosteal implants with titanium sprayed surfaces. J. maxillofacial surgery 9:15.

- Sekiguhi J. (1992). An attempt to measure viscoelasticity of human facial skin by impact hammers method [in Japanese]. Kanagawa Shigaku 26:387-411.

- Sennerby L, Meredith N. (2008). Implant stability measurements using resonance frequency analysis: Biological and biomechanical aspects and clinical implications. Periodontol 47:51-66.

- Sennerby L, Thomsen P, Ericson LE. (1993). Early tissueresponse to titanium implants inserted in rabbit cortical bone. 1. Lightmicroscopic observations. J Mater Sci Mater Med 4: 240-250.

- Shapoff CA, (2002). Clinical advantages of tapered root form dental implants. Compend Contin Educ Dent 23, 42-44, 46, 48.

- Shokri, M., \& Daraeighadikolaei, A. (2013). Measurement of primary and secondary stability of dental implants by resonance frequency analysis method in mandible. International journal of dentistry, 2013.

- Steigenga, J. et al. (2004). Effects of implant thread geometry on percentage of osseointegration and resistance to reverse torque in the tibia of rabbits. J Periodontol, 75, 1233-124.

- Sullivan DY, Sherwood RL, Collins TA, Krogh PH. (1996). The reverse-torque test: A clinical report. Int J Oral Maxillofac Implants 11:179-85. 
- Summers RB: (1994). A new concept in maxillary implant surgery: The osteotome technique. Compendium 15, 152, 154-156, 158 passim; quiz 162

- Swami V, Vijayaraghavan V, Swami V. (2016). Current trends to measure implant stability. J Indian Prosthodont Soc 16:124-30

- Teerlinck J, Quirynen M, Darius P, van Steenberghe D. (1991). Periotest: an objective clinical diagnosis of bone apposition toward implants. Int J Oral Maxillofac Implants; 6:55-61.

- Tovar N, Marin C, Teixeira HS, Anchieta RB, Silveira LM. (2014). The impact of a modified cutting flute implant design on osseointegration. Int J Oral Maxillofac Surg; 43:883-888.

- Turkyilmaz I, Tozum TF, Tumer C, Ozbek EN: (2006).
Assessment of correlation between computerized tomography values of the bone, and maximum torque and resonance frequency values at dental implant placement. J Oral Rehabil 33, 881-888

- Valderrama P, Oates TW, Jones AA, Simpson J, Schoolfi eld JD, Cochran DL. (2007) Evaluation of two different resonance frequency devices to detect implant stability: A clinical trial. J Periodontol 78:262-72.

- Yadav P, Tahir M, Shetty P, Saini V, Prajapati D. (2016). Implant design and stress distribution. Int J Oral Implantology Clin Res 7(2): 34-39.

- Yamaguchi, Y., Shiota, M., Munakata, M., Kasugai, S., \& Ozeki, M. (2015). Effect of implant design on primary stability using torque-time curves in artificial bone. International journal of implant dentistry, 21. 